\title{
ON THE NECESSITY OF CHANGES IN THE STRATEGY OF UTILIZATION SHIP BOILER TECHNICAL CONDITION MAINTENANCE IN THE ASPECT OF LNG APPLIED AS FUEL
}

\author{
Andrzej ADAMKIEWICZ \\ Maritime University of Szczecin \\ Wojciech ZEŃCZAK \\ West Pomeranian University of Technology
}

\begin{abstract}
:
Heavy oils (HFO fuels) used on ships play a part in degradation of technical condition of heat exchange surfaces of utilization boilers especially on the exhaust gas side. Presence of sulphur in these fuels is the main factor favouring degradation. The upper limit for sulphur content in the fuel used outside the SECA areas equal to $3.5 \%$ is currently in force, at least until the year $\mathbf{2 0 2 0}$ or $\mathbf{2 0 2 5}$. The recommended by classification societies overhauls of utilization boilers are, therefore characterized by a specially chosen strategy thanks to which it is possible to maintain their appropriate technical condition. The requirement to use fuels with low sulphur content (LSFO), which are significantly more expensive than MDO fuels, in the areas of controlled sulphur emissions also led to a further introduction of alternative fuels, such as methanol and above all liquefied natural gas (LNG), onto ships. That is especially valid for the ship owners whose vessels e.g. ferries sail mainly within SCECA This article analyses the consequences of the introduced fuel change on utilization boiler maintenance. A change in the technical condition maintenance strategy for utilization boilers has been suggested.
\end{abstract}

Key words: utilization boiler, technical condition, maintenance strategy, gas as a ship fuel

\section{INTRODUCTION}

At present one of the most important challenges for seafaring industry are the introduced by the International Maritime Organization (IMO) areas of controlled emissions (ECA) and the requirements on limited emission of toxic compounds in European Union harbours. The basic problem for ship owners is maintaining the accepted level of sulphide oxide $\mathrm{SO}_{x}$ emissions in exhaust gases. Their acceptable emission is restricted by the introduced limits of sulphur content in the fuel. In the SECA - SO Emissions Controlled Areas, to which among others belongs the Baltic Sea, the acceptable limit since 01.01 .2015 is $0.1 \%$. It is permitted to alternatively use systems reducing and monitoring in a continuous way the content of $\mathrm{SO}_{\mathrm{x}}$ in exhaust gases at least to the level resulting from the application of a fuel with an acceptable amount of sulphur. European Union countries are mainly guided by IMO regulation with the exception that the stricter regulations on sulphur oxide emissions went into power earlier i.e. on 1st January 2010. They are obligatory in harbour areas of the whole Union and make it obligatory to use fuels containing no more than $0.1 \%$ sulphur for seagoing and inland vessels when staying at harbours. While sailing outside the areas of $\mathrm{SO}_{\mathrm{x}}$ control (SECA) the currently in force, at least until the year 2020 or $2025,3.5 \%$ is the upper limit for sulphur content in the fuel.

In order to reduce $\mathrm{CO}_{2}$ emissions since $1^{\text {st }}$ January 2013 all new-built ships exceeding $400 \mathrm{BRT}$ are required to have an Energy Efficiency Design Index (EEDI), whereas all ships, that is both new and those constructed before that date, are covered by Ship Energy Efficiency Plan (SEEMP) ensuring optimum ship operation [10].

Moreover, on voluntary basis, Energy Efficiency Operational Indicator (EEOI) is used. It allows current evaluation of ship transport efficiency, which can be a supplement for SEEMP [13]. Most probably starting from 2021 further restrictions on nitrogen oxide $\left(\mathrm{NO}_{\mathrm{x}}\right)$ emissions are being planned.

As the main component of natural gas is methane $\left(\mathrm{CH}_{4}\right)$, whose ration of hydrogen to carbon atoms is the most advantageous out of those for all hydrocarbons, it is characterized by lower $\mathrm{CO}_{2}$ emissions than it is the case when any other oil fuels are burned. Therefore, LNG is highly recommended as a ship fuel. Its higher calorific value is not also without significance when compared to other liquid ship fuels, as it nearly reaches $50 \mathrm{MJ} / \mathrm{kg}$ which gives $10 \%$ more energy from $1 \mathrm{~kg}$ of fuel. Burning LNG in ship engines gives as a result $\mathrm{CO}_{2}$ emissions lower by $25 \%$ in comparison to that from Marine Diesel Oil (MDO), while its $\mathrm{SO}_{\mathrm{x}}$ and solid particle emissions are in this case practically eliminated.

Application of natural gas as ship fuel took place together with the introduction, at the beginning of the sixties of the last century ships, called LNG carriers, destined for transporting this fuel in the condensed form. While transported at a temperature below $-160^{\circ} \mathrm{C}$, despite very good insulation, heat penetration from the environment to the cargo tank is unavoidable. Part of the cargo evaporates and has to be removed from the tank so as not to let the pressure increase excessively. The amount of evaporated gas is 
in the range of 0.20 to $0.25 \%$ of the carried cargo per day. This gas was initially used to feed boilers as from the start of LNG transportation by sea, ships with steam power turbines have been used. Relatively low efficiency of steam turbine power plants and technological progress in ship industry led to the concept and construction of gas carriers powered by diesel engines supplied by two kinds of fuel: diesel oil and also the gas transported as cargo. In this way it was possible to significantly increase the efficiency of the power system and at the same time solve the problem of removing the evaporated gas from the cargo area.

Dual fuel diesel engines have been on the market for more than 20 years, however, for a long time ship owners preferred a steam turbine power plant. Despite its significantly lower efficiency, there are numerous reasons for which it was used. These include its reliability, easy and fast start- up, non-specific fuel type and favourable costs of lubrication oil, repairs and servicing. On the newly built LNG carriers dual fuel diesel engines are the basic source of power.

Special properties of the adjusted technologies of LNG application for gas carrier power plants at the beginning of the $21^{\text {st }}$ century became an impulse for their transfer onto other type of ships due to the appearance of SECA areas.

Ship owners facing a choice of using expensive fuels with low sulphur content or installing expensive systems for removing sulphur compounds from exhaust gases (the so called scrubers) are more often inclined to choose LNG as fuel. Slowly methanol is also introduced onto ships as an alternative fuel. So far only a few vessels have been adjusted to use it - the first one in 2015. LNG as a ship fuel has a much longer history. The first ship running on LNG, introduced in the year 2000, was the shuttle ferry Glutra operating in Norwegian fiords. At the moment, only in Norway, there are more than 40 vessels using this type of fuel. A breakthrough in the use of LNG for driving ships was the introduction of a big ferry (2800 pasengers and a crew of 200) "Viking Grace" serving the route Turku-MarienhamnStockholm. Four dual-fuel engines Wärtsila 8L50DF each of $7600 \mathrm{~kW}$ are used as the main power. Heating steam is generated by two dual-fuel auxiliary boilers of $7 \mathrm{Mg} / \mathrm{h}$ efficiency and four utilization boilers of $2.05 \mathrm{Mg} / \mathrm{h}$ efficiency each [8].

Exhaust gases from LNG burning on ships without sulphur compounds and solid particles practically cease being aggressive towards heated surfaces of boilers. Applying LNG as an alternative to marine diesel oil stimulates the need to modify the strategy of utilization boiler maintenance which can lead to lowering operational costs.

\section{INFLUENCE OF BURNING PRODUCTS OF DIFFERENT KINDS OF FUEL ON THE TECHNICAL CONDITION OF UTILIZATION BOILER ELEMENTS}

Contemporary self-ignition ship engines are supplied with marine fuels which contain elements such as carbon, hydrogen, sulphur, oxygen, nitrogen and traces of other elements. In the process of fuel burning these elements become oxidated in an exothermal reaction whose products are emitted as a mixture of gases such as: carbon dioxide $\left(\mathrm{CO}_{2}\right)$, steam $\left(\mathrm{H}_{2} \mathrm{O}\right)$, sulphur dioxide $\left(\mathrm{SO}_{2}\right)$. Additionally the exhaust flux contains nitrogen oxides $\left(\mathrm{NO}_{\mathrm{x}}\right)$, small amounts of carbon monoxide (CO) and unburned hydrocarbons as well as nitrogen and oxygen from the air supplied for burning and also small quantities of unburned fuel. The rest are the combustible solid particles (soot) and noncom- bustible ones i.e. ash. Many of these compounds have corrosive properties and when they deposit on the heat exchange surfaces, they hinder heat transfer into the working medium.

In the case when ship engines are supplied with the required low-sulphur distillates or the marine oils (LSDO or LSFO) in the SECA areas instead of the so-far used fuels, one should still take into account the possibility of a set of similar threats to boiler operation on ships. Low content of sulphur in the fuel protects utilization boilers practically only from low-temperature corrosion, as they are designed in such a way so that the fuel dew point is not reached when fuels of the outside SECA areas with acceptable 3.5\% sulphur content are used. Temperature of exhaust at the exit of the utilization boiler should not therefore exceed $160-165^{\circ} \mathrm{C}$. Lower exhaust temperatures, depending on the sulphur content in the fuel, might be below the dew-point. A relationship between the approximated exhaust dewpoint and sulphur content in the fuel is shown in Fig. 1 [5].

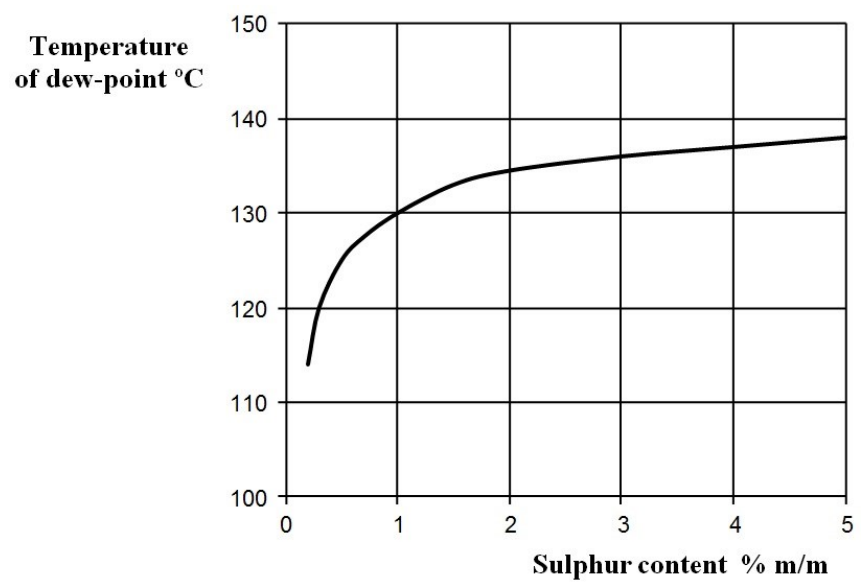

Fig. 1 Relationship between the approximated exhaust dewpoint and sulphur content in the fuel Source: [5].

In the case of an inappropriate boiler servicing, explosions and fire can take place in the boiler working areas on the heat exchange surfaces. They are favoured by more pronounced soot depositions on the heated surfaces. Such situations may especially arise during uncontrolled overloading of diesel fuels cooperating with utilization boilers, faulty exhaust blow or lack of heat reception from exhaust gases [3]. An example of destruction of a connection between a boiler and a collector of exhaust outlet throughout blowing out a seal as a result of fire and an explosion inside the boiler and as a consequence in the vicinity of boiler mounting is shown in Fig. 2.

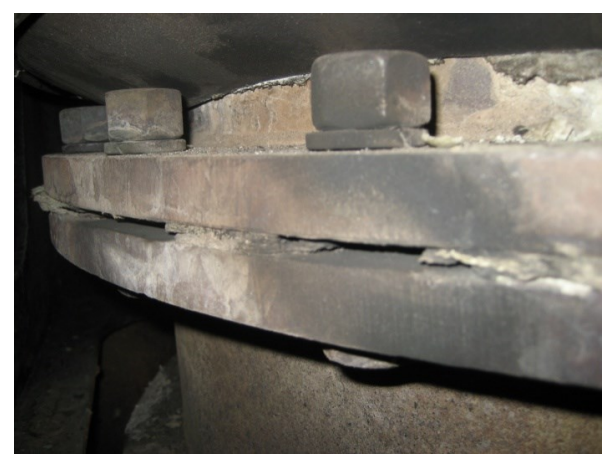

Fig. 2 View of a blown out seal in the connection of the boiler with the exhaust collector of a utilization thermal-oil boiler 
Comparison of emissions from engines of the 7OME type when HFO and LNG are burned

HFO

LNG

Estimated emissions 6S70ME-C

$\begin{array}{lc}\text { Component } & \text { Value } \\ \mathrm{CO}_{2}[\mathrm{~g} / \mathrm{kWh}] & 577 \\ \mathrm{O}_{2}[\mathrm{~g} / \mathrm{kWh}] & 1359 \\ \mathrm{CO}[\mathrm{g} / \mathrm{kWh}] & 0.64 \\ \mathrm{NO}_{\times}[\mathrm{g} / \mathrm{kWh}] & 11.58 \\ \mathrm{HC}[\mathrm{g} / \mathrm{kWh}] & 0.19 \\ \mathrm{SO}_{\times}[\mathrm{g} / \mathrm{kWh}] & 10.96 \\ \mathrm{PM}\left[\mathrm{mg} / \mathrm{m}^{3}\right] & 0.54\end{array}$

Exhaust gases from LNG burning on ships are without sulphur dioxide, contain fewer solid particles and as a result they practically cease to be aggressive towards the heated surfaces of utilization boilers. It opens a significant possibilities of heat utilization of engine exhaust both in the case of the diesel as well as the gas turbines ones. When natural gas with only traces of sulphur content is burnt, exhaust dew-point is close to that of atmospheric air. Thus, there is a practical possibility to build the so-called condensation boilers as it is the case in land heating systems where there are no fears concerning degradation of heat exchange surfaces. Therefore, theoretically it is possible to increase the utilization of the heat flow in the engine exhaust about twofold. Table 1 shows a comparison of emissions of MAN $B \& W$ two-stroke ship engines of the $6 S 70 \mathrm{ME}-\mathrm{C}$ and $6 \mathrm{S70}$ ME-GI types. The first of them was supplied with HFO, whereas the other one with LNG. It has to be added that engines fed with the latter are always also supplied with a small dose of pilot oil in the amount equal to about $5-8 \%$ of the normal quantity of the liquid fuel, whose aim is to bring about the ignition of gas. As a result there are some solid particles in the exhaust.

A higher calorific value of LNG in comparison to those of marine oils is also quite meaningful as it results in higher temperature of exhaust leaving the engine and being directed towards the utilization boiler. In this case the temperature of exhaust just before utilization boiler coils is important [11].

As LNG is a fuel with a different molecular structure, and thus of other properties (in comparison to traditional marine fuels) which contribute to complete and total burning on heat exchange surfaces, therefore, as it has been mentioned, deposition of soot and other materials will be less pronounced. Thus, there is a justified need for changing the utilization boiler maintenance method in the case of boilers supplied by exhaust from LNG [11].

In a general case the most frequent causes of utility boiler breakages are the following:

- formation of deposits on coil surfaces which hinder heat exchange and as a result lower boiler efficiency,

- erosion, corrosion, and cavitation which can be caused by polluted water and non-designed operational states,

- lack of leak tightness, leakages,

- insulation damage,

- water pump faults $[4,6]$.
Utility boiler breakdowns take place as a result of:

- non-functioning of water level detectors in the boiler and therefore the supplying pump not getting switched on, which leads boiler coils burning out resulting in their leakages or destruction:

- lack of regular skimming of boiler operational space,

- faulty working medium flow through boiler coils,

- abnormal working media properties (particularly in the case of thermal oil),

- point-wise coil burnouts caused by carried particles of unburned fuel which get burned down completely on coil surfaces causing local overheating,

- deposition of significant amounts of soot leading to coil overheating, ignition of these deposits and boiler fire.

Switching to LNG should significantly eliminate the above described faults and breakages connected with the exhaust boiler side.

\section{TERMS OF UTILIZATION BOILER CONDITION MAINTE- NANCE REGARDING THE TYPE OF WORKING MEDIUM}

Systems generally used for utilization of waste energy are based on water, steam or more rarely thermal oil as working media. In steam systems it is possible to apply utilization steam turbines. However, the extent to which thermal energy from exhaust is utilized is limited among other factors by the size of utilization boilers. The solution to the problem is possible thanks to applying working media with low evaporation enthalpy like for example organic substances. Rankine's cycles using such substances are denoted as ORC (Organic Rankine Cycle). A significant advantage of ORC systems over the conventional ones is due to the possibility of cooling exhaust till its dew-point without the necessity of an excessive extension of the utilization boiler. Because of this, there is a noticeable increase of waste energy utilization which directly leads to the increase of energy efficiency of the ship power plant.

In the case of steam utilization boilers the monitored signal in applied diagnostics is the steam pressure in the boiler. The required steam pressure $\left(p_{\text {steam }}=\right.$ idem $)$ is maintained using gates regulating the flow of exhaust through the boiler or directing a part of the steam flux into an excess condenser. The position of gates is regulated by servo- 
motors controlled by the signal of the steam pressure in the boiler.

In utilization boilers with thermal oil, regulation of heat flow throughout redirecting the exhaust flux is not to be done. In the case of excessive heat flow, part of the oil is directed to the cooler, an equivalent of a condenser in steam systems. In boilers of this type maintaining an appropriate temperature of the oil film, below the limiting value, is important having in view faultless operation of the boiler. Its value is given in certificate papers and those confirming that the boiler is ready for operation. As temperature measurement is technically complicated, its value is maintained indirectly throughout the mean temperature of oil and the speed of oil flux. Moreover, installations are equipped in systems counter-reacting to excessive temperature increase as well as in a system ensuring appropriate oil flow. The oil installation should be designed in such a way that the volume of oil flowing through the boiler would be constant, independent of the number of attached heat receivers. Stability of this flow is ensured by bypassing pipes which are connected throughout a three-way valve with the inlet and the discharge pipes [1].

The oil pressure in utilization boiler circulation is also monitored as well as the difference in pressures on control orifices of boiler sections which enables to control the leak tightness of particular sections and loss of oil at cracks.

These issues determine existing differences between steam and thermal oil boilers which lead to the rules regarding their maintenance and diagnosing.

In the case of ORC systems it might be advantageous to apply a once-through boiler. This is because of a shorter period of time in which the working medium is exposed to high temperature and whose intensity of thermal decomposition depends on the value of temperature and the time of exposure. However, it has to be noted that in the boiler proper a part of the tubes are dry (only dry saturated steam flows through them). Such a situation combined with high exhaust temperature may lead to a faster decomposition of the organic substance. Carbon, which is usually the product of this decomposition, deposits on the tubes causing the increase in hydraulic resistance and resistance accompanying heat exchange. Such phenomenon could be avoided in systems operating at supercritical parameters, when the process of phase change does not take place in the heat exchanger. Another drawback of once-through boilers is their small thermal inertia which is especially important for ship safety. In the case of an emergency main engine interruption, steam generation feeding the turbogenerator is almost instantly finished. Therefore, for ship ORC systems boilers with forced circulation are recommended [5].

In ship utilization systems the considered organic media have to be classified as non-flammable It eliminates the danger of an explosion in the case of leaking, however the leaks themselves are a problem. The increase of content in the air of any, even the most harmless substance, causes the decrease of oxygen content. Such an environment may be dangerous for humans. Therefore, in order to maintain the content of substance vapours below the limiting allowable concentration (TLV), very good ventilation of the engine room has to be provided.

Generally, maintenance of utilization boilers after their switching to LNG should not be a reason to change the technical condition maintenance strategy solely due to the fact that there is another working medium.

\section{DIAGNOSTIC PARAMETERS OF UTILIZATION BOILERS}

The source of diagnostic information on ship utilization boilers are the parameters of the main operational process which is the heat exchange between the products of fuel burning i.e. exhaust gases from self-ignition engines and the water and steam or thermal oil or low-boiling organic medium (in the case of an ORC installation) taking into consideration constructional material of the boiler. Parameters of the heat-flow signal are an integral component of the system regulating and controlling operation of boilers [4].

Supervision of boiler operation is mainly carried out basing on the values of thermodynamic parameters - the thermal-flow signal and visual diagnostic methods. Reduction of heating power and the mass flux of steam or oil, too high temperature of exhaust exiting the boiler, occurrence of smoky exhaust in comparison to nominal values are all specific diagnostic pieces of information. Therefore it is necessary to monitor the decrease of temperature before and after the utilization boiler, the values of working media pressures, $\mathrm{pH}$ and chemical quality of the supplying water which affect sedimentation of calcium compounds and other harmful sediments (in the aspect of heat exchange and corrosion) on inside walls of heat exchange surfaces and in the case of the oil boiler - the temperature of the oil film.

When LNG is applied a reflection of the technical condition of boiler heated surfaces may be the quality of heat transfer from the exhaust to the working media (water and thermal oil or low-boiling organic medium). Such a thesis enforces basing diagnostic studies on the maintenance auxiliary boiler technical condition on the values of transfer coefficient of the heated surfaces which are covered with deposits of burning products. Detailed sets of controlled values as diagnostically useable will depend on the type of boiler (steam, thermal-oil or a low-boiling medium) and constructional solutions of regulation equipment. Steam pressure and the temperature of the working medium are inseparably connected with faultless operation of the ship power system and safety of the crew. In special cases vibroaccoustic and thermo-visual methods can be used to determine and locate faults.

Additionally values of diagnostic parameters obtained from monitoring and control of utilization boiler operation can be accepted as diagnostic signals of the main engine (for example the increase in exhaust temperature before the utilization boiler gives information on valves, injectors, quality of the burning process). Therefore, a decrease in the number of diagnostic parameters in particular signals cannot be the aim of its own, but it should be the result of the accepted optimization criterion of the control system in the issue of monitoring operational parameters of the elements of a ship power system.

\section{MAINTENANCE METHODS OF UTILIZATION BOILERS SUP- PLIED BY LNG EXHAUST GASES}

In respect to auxiliary steam boilers different operational procedures can be used. They are derived from strategies currently applied for technical facilities, i.e.:

1. Planned Preventive Maintenance (PPM) which takes into account periodical, planned overhauls and servicing activities (static - at present, to the highest extent applied for steam boilers),

2. Condition Based Maintenance (CBM) - dependent on the current boiler condition (dynamic),

3. "From emergency to emergency" - Fix it When it Breaks (FWB), 
4. Reliability Based Maintenance (RBM) - directed at reliability (boiler partially serviceable),

5. Total Lifecycle Costs Strategy (TLC) - aiming to minimize operational costs,

6. Total Productive Maintenance (TPM) - directed at maximum boiler efficiency, or other methods also personalized adjusted to a specific kind of technical facility [2].

Development of shipbuilding technology and ecological restrictions in ship transport made classification societies systemize the methods of maintenance of elements of ship power systems and at the same time adjust them to regulations and IMO convention. They comprise Alternative Systems of Machinery Survey $[7,9]$ :

1. Continuous Machinery Survey (CMS) carried out by the classification society throughout direct overhauls of particular elements of equipment/boilers or acceptance of overhauls performed by the chief ship's engineer which is a combination of the "from emergency to emergency" - FWB strategy, the one oriented at reliability (boiler partially serviceable) - RBM and the one directed at the maximum boiler efficiency - TPM.

2. Survey arrangement based on approved planned maintenance scheme (PMS) realized throughout overhauls based on cyclic servicing recommended by the manufacturer, those resulting from ship owner's experience and from the use of a computer diagnostic system, if it was applied, and which is the execution of the PPM method.

3. Condition - based monitoring (CBM) which is an attempt to implement, in respect to ship boilers, diagnostic maintenance methods as a combination of the PPM (Planned Preventive Maintenance) and CBM (Condition Based Maintenance) with the use of continuous technical diagnostics at boiler operation performed by the diagnostic system extended by the expert system and neuron networks. In this method some of the utilization boiler parameters should be monitored on-line, while others off-line.

Application of continuous diagnostics cannot exclude the so-far used periodical technical diagnostics (partially within classification society's supervision PPM). This method in respect to utilization boilers is carried out when the boiler is not in operation and only sporadically during its operation. In such a case, a partial dismounting is required or at least application of some specialist techniques comprising:

1. Regular performance tests - done at boiler operation after it has been switched on and when it is thermally stable, after the boiler has been serviced, before it has been serviced or modernized,

2. Evaluation of its construction condition,

3. Metallographic diagnostics,

4. Evaluation of the condition of its heated surfaces, etc.

So far an inspector from a classification society relied on the time criterion for annual inspections, for class confirmation and renewal. During inspections boiler technical condition, its protection and leak tightness are checked. Time periods are basically non-changeable, however, the can be moved, but only in a limited period of time which is due to the classifying status. However, inspection period within boilers have not changed as the working medium has not been altered. What can be discussed is the overheating of utilization boiler coils in the aspect of possible cocking of thermal oil in the circulation system especially due to higher exhaust gas temperature at LNG burning.
Therefore, there is a need for TBM (Time Based Maintenance) implementation for LNG exhaust supplied boilers, with a possible modification comprising lengthening time periods between overhauls and reduction of servicing activities. This approach is justified by a more and more precise and reliable diagnostics which is a real part of maintenance based on boiler condition (operational diagnostics thermalflow and thermo-visual) as well as a part of servicing and repairs (non-operational diagnostics: endoscopic inspections and destructive testing) $[2,6]$.

\section{SUMMARY}

The presented conditions of auxiliary utilization boiler operation on seagoing ships restricted rather than stimulated creation of strategies of technical condition maintenance based on economic optimization of technology and safety [4].

The aim of servicing in the process of utilization boiler maintenance is recreating its technical condition, eliminating the possibility of occurrence of faulty operation in a predictable way. Applying LNG as fuel should lead to drawing up new procedures both for maintenance and operational activities at least due to switching from one type of fuel to another (e.g. from LSFO to LNG) in dual-fuel engines. The procedure of soot washing and burning-out should be simplified (smaller amount of chemicals used, different frequency of such activities). Dynamics of processes will be different due to exhaust gas temperature at the entrance to the boiler and its decrease at coils.

The worked out common methods for both the steam and thermal oil boiler maintenance should prove their universality. The expected cost reduction should result from avoiding breakages and earlier signals of faults thanks to the application of new surveying methods adjusted to the new kind of fuel (LNG) also accounting for the type of ship.

\section{REFERENCES}

[1] G. Ackerman, "Supply and disposal systems", in Compendium Marine Engineering, $\mathrm{H}$. Meier-Peter and $\mathrm{F}$. Bernhard, Eds., Hamburg: Seehafen Verlag, 2009, pp. 724-729.

[2] A. Adamkiewicz and A. Burnos, "Influence of maintenance strategies on the reliability of gas turbines in power systems of floating production, storage and offloading units (FPSO)", in Proc. of 28th International Scientific Conference DIAGO ${ }^{\circledR}$ 2009. Technical diagnostics of machines and Manufacturing equipment, Czech Republic, Ostrava, Rožnov pod Radhoštěm, 2009, pp. 5-13.

[3] A. Adamkiewicz and J. Fydrych, "Application of an exhaust signal for diagnosing a ship boiler", Journal of POLISH CIMAC. Diagnosis, Reliability and Safety, vol. 3, no. 2, 2008, pp. 15-23.

[4] A. Adamkiewicz and K. Kołwzan, "Application of generated signals to control the operation of ship boilers", Polish Journal of Environmental Studies, vol. 18, no. 2A, 2009, pp. 5-10.

[5] A. Adamkiewicz, R. Michalski and W. Zeńczak, Wybrane problemy technologii konwersji energii w okrętowych systemach energetycznych, Lublin: KAPRINT, 2012.

[6] A. Adamkiewicz and W. Zeńczak, "Diagnosing Auxiliary Ship Boilers With The View Of Using LNG As Fuel", in Proc. of 28th International Scientific Conference DIAGO ${ }^{\circledR}$ 2009. Technical diagnostics of machines and 
Manufacturing equipment, Czech Republic, Ostrava, Rožnov pod Radhoštěm, 2014, pp. 5-16.

[7] Alternatywne Systemy Nadzoru Urzq̨dzeń Maszynowych. Publikacja $\mathrm{Nr} 2 / \mathrm{P}$, Polski Rejestr Statków, Gdańsk, Poland, 2015, pp. 5-18.

[8] "First big ferry fuelled by natural gas", HANSA International Maritime Journal, no. 6, June 2013, pp. 3643.

[9] Guidance For Condition Monitoring. Classification Notes No. 10.2., Det Norske Veritas, Høvik, Norway, 2008, pp. 5-8.
[10] Information in Annex 8 Resolution MEPC.212

(63) [Online]. Avaiable: htpp://www.imo.org

[11] T. Mattila, "LNG As A Fuel For Shipping", Gasum, no. 12, June 2013, pp. 1-9.

[12] ME-Gl Dual Fuel MAN B\&W Engines, MAN Diesel, Copenhagen, Denmark, 2009, pp. 10.

[13] T. Mundt and M. Köpke, "MEPC 62: Energy Efficiency Design Index verabschiedet", Schiff \& Hafen, no. 9, Sept. 2011, pp. 12-15.

dr hab. inż. Andrzej Adamkiewicz, prof. AM

Maritime University of Szczecin, Faculty of Mechanical Engineering

Wały Chrobrego 1-2, 70-500 Szczecin, POLAND

e-mail: a.adamkiewicz@am.szczecin.pl

dr hab. inż. Wojciech Zeńczak, prof. ZUT

West Pomeranian University of Technology, Szczecin

Faculty of Maritime Technology and Transport

al. Piastów 41, 71-065 Szczecin, POLAND

e-mail: wojciech.zenczak@zut.edu.pl 